\title{
A CONTRIBUTION TO THE STUDY OF CALCAREOUS CONCRETIONS IN THE BRAIN.
}

\author{
By F. B. Mallory, M.D., Boston. \\ From the Pathological Anatomical Institute of Professor Chiari in Prague.
}

(Plate IV.)

THE case which forms the basis of this paper showed two pathological processes present in a marked degree and intimately combined in the blood vessels of the brain, leading to atrophy of considerable portions of nervous tissue, without there having been noted during life any abnormal mental symptoms.

These two pathological processes are colloid inflitration and calcification. The calcification only was detected macroscopically, and it was noted as occurring in three forms-as rigid blood vessels projecting like ends of wire from the cut surfaces of the brain, as fine sandlike deposits, and as stonelike concretions up to the size of barley grains.

The case was studied with particular reference to three points, namely, the location of the colloid material with reference to the blood vessels, the relation between the colloid material and the calcification, and the origin of the sandlike deposits and stonelike concretions.

The following is extracted from the autopsy record:-

Woman, 45 years old.-Autopsy, April 29th, 1891. Surgical Clinic, Prof. Gussenbauer.

Clinical diagnosis.-Morbus Brightii chronicus. Parotitis dextra. Bronchitis catarrhalis. Pneumonia lobularis sinistra.

Pathological anatomical diagnosis. - Morbus Brightii chronicus cum atrophia granulari renum. Hypertrophia excentrica ventriculi cordis sinistri. Endarteritis chronica deformans. Parotitis suppurativa dextra. Pneumonia lobularis bilateralis. Calcificatio arteriarum cerebri et cerebelli. Nodi calcarei cerebelli.

Brain (Mus. No. 4745). - The scalp pale. The calvaria $49 \mathrm{~cm}$. in circumference, long, thicker especially in the anterior and posterior parts. The sagittal suture obliterated. The dura more adherent than normal to the internal surface of the skull. The internal meninges not thickened, easily removable from the surface of the brain. The basal arteries in general thin walled. The ventricles of the brain not dilated. The substance of the brain pale, and a little more moist than normal. In the pons numerous fresh punctate hæmorrhages. In the white substance on all the cut surfaces of the whole cerebrum numerous small rigid calcified arteries projecting from the brain substance like ends of , wire. 
The same alteration of the blood vessels as in the cerebrum on the horizontal cut surfaces through the cerebellar hemispheres in the dentate nucleus and in the medullary substance. Here and there also fine sandlike deposits in the brain substance of the cerebellum; and, finally, in the inner layer of the cortex of the cerebellum stone-like concretions up to the size of barley grains.

The material for microscopical examination consisted of a vertical section through the gyrus centralis anterior of the right half of the cerebrum (sectio frontalis of Pitres), of the whole of the right half of the cerebellum, and of the pons and medulla. The position of each piece, cut and mounted from the above mentioned parts, was carefully noted; so that, when the work was finished, and the drawings of the various slide preparations were joined together, they showed one frontal section through the whole of the right half of the cerebrum, and three frontal sections through the right half of the cerebellum, one through, the other two anterior and posterior respectively to the dentate nucleus.

In the pons and medulla no pathological changes in the blood vessels could be found.

The intima of the basilar artery was considerably thickened in places from chronic endarteritis, but the vessel showed no other changes.

The pieces of brain tissue were imbedded in celloidin. After a number of sections had been cut, the blocks were put into 5 per cent. nitric acid for from 1 to 2 days, to decalcify. They were then thoroughly washed in water, and hardened in 80 per cent. alcohol for cutting again. In this way the differences between the sections before and after decalcification could easily be compared. The most useful stain was found to be Delafield's hæmatoxylin. Sections were stained in the strong solution for from 1 to 4 minutes, and then left in plenty of distilled water over night. By this method the colloid material was always sharply defined, taking a considerably deeper stain than the nuclei, and of a slightly blue tint. The calcified material either did not stain, or acquired a somewhat reddish blue tint. The fatty crystalline deposits often present in great abundance (on account of the calcification the tissue had been hardened in alcohol), were but lightly and rather diffusely stained, so that they could easily be distinguished from the colloid. Alum cochineal was also used, but the differentiation of the various parts was not so good. For contrast between the colloid material and the nuclei, Van Gieson's method, or even better, Weigert's fibrin stain was found serviceable.

A number of the stonelike concretions were picked out, decalcified, and sections cut and stained. Numerous arteries and capillaries were also teased out. Some were mounted before, others after decalcification, others again were stained. Tested with strong sulphuric acid, the calcified vessels were quickly covered with innumerable fine needleshaped crystals.

Before beginning the description of the pathological changes found 
microscopically, it may be stated that the lime salts were found nowhere except in transparent colloid material as a basis for the deposit.

Cerebrum.-The changes in the arteries, in the precapillaries and capillaries, and in the veins will be taken up in order.

Nearly all of the arteries had calcified walls, often of great density. The middle coat was always the first and most markedly affected (Plate IV. Fig. 1). The process gradually extended, however, into the adventitia, and not infrequently also into the lumen of the vessel, gradually obstructing it. After decalcification a homogeneous, highly refractive, transparent substance was found occupying the position previously held by the lime salts. In the earliest stages of the process in the muscular layer the transparent drops seemed to lie to some extent within the muscle fibres, and even to encroach upon the nucleus. But judging from the way in which the colloid material spread out and coalesced into irregular masses, the change must also take place between the cells. As the process advanced, the muscular coat disappeared. In the adventitia small transparent drops made their appearance, often coalescing into irregular masses. Even in the most calcified arteries, however, a trace of the adventitia could usually be found on the outside of the vessel. On the inside of the arteries the colloid material often projected into the lumen irregularly (Plate IV. Fig. 2); or in the form of a broad or narrow ring, gradually occluding it (Plate IV. Fig. 3). So long as the vessel remained pervious, the endothelial cells of the intima were unaffected.

In the preccuillavies and capillaries the colloid material made its appearance as fine drops in the wall between the inner and outer surfaces, and apparently irregularly, without reference to the nuclei of the cells (Plate IV. Fig. 4). Even the very smallest drops stained intensely with hæmatoxylin. They gradually increased in size and joined one another so as to encase the vessel in a thick, homogeneous, highlyrefractive, nodular wall (Plate IV. Fig. 5). Some of the masses in the walls were much larger than others, and had a concentric appearance. Excepting the very small drops, all this colloid material was infiltrated with lime salts.

In the veins the colloid material was present in much less abundance, usually as small or large drops in the media, or in the inner layer of the adventitia (Plate IV. Fig. 6).

The changes in the precapillaries and capillaries, which formed the most interesting feature of this case, were not equally distributed throughout the brain substance of the cerebrum, but were confined mainly to certain localities. They were to be found to some extent in the white matter, more particularly in the neighbourhood of the ganglia, but they were most extensive here and there in those parts of the grey matter of the cortex which were nearest the ganglia, as, for instance, at the base of the sulcus between the middle and inferior frontal convolutions and in the basal ganglia. The largest of these areas measured 
over $1 \mathrm{~cm}$. in extent. In these places nearly the whole of the anastomosing network of blood vessels was changed into a calcified, irregular, nodular, branching framework, showing in the spaces occasional ganglion and small cells, with here and there a blood vessel whose walls showed no pathological change. In a few small areas the spaces between the capillaries were filled with calcified colloid material, so that small concretions were formed.

In the cerebellum the pathological changes were even more remarkable and interesting than in the cerebrum. All of the arteries lying in the white matter and within the dentate nucleus had calcified, often nodular walls, and not infrequently the lumen was occluded. But it was in the smallest blood vessels that the greatest change had taken place. In the dentate nucleus all the capillaries, almost without exception, rumning between the ganglion cells had thickened calcified walls, and formed an intricate network, in the interstices of which were a few ganglion and small cells (Plate IV. Fig. 7). In places the tissue between the capillaries had completely disappeared, and the spaces had become filled up with calcified colloid material binding the vessels together, so that concretions were formed.

In the granular layer of the cortex, nearest the central white matter, the capillaries had become transformed in the same manner as in the dentate nucleus, into a calcified network, but the intervening spaces had become filled up to a much greater degree by colloid material which afterwards had become calcified, so that numerous very hard nodular concretions had been formed often measuring $5 \mathrm{~mm}$. in length and 2 to $3 \mathrm{~mm}$. in diameter.

All of the concretions picked out of the brain tissue of the cerebellum proved, on examination, to be either portions of the granular layer or of the dentate nucleus. A section through one of these concretions after decalcification showed many wavy, twisting lines, usually arranged in many layers (Plate IV. Fig. 8). The colloid substance in these areas, judging from its reaction to stains, was of varying density. The capillaries could still be recognised by their deeper colour, and it was around them that the various successive layers of colloid had been deposited. This could be seen to best advantage in cross sections of the vessels.

In many places the granular layer had been almost completely destroyed. The molecular layer surrounding these concretions was frequently reduced to a half, or even a third of its normal thickness. Purkinje cells could still be found, but they were very few in number.

The capillaries in the molecular layer afforded the best opportunity for the study of the deposit of the colloid substance, for the process here was rarely far advanced. In a few places, however, the capillaries here were changed into many-layered, solid, contorted tubules, which, on section, gave the appearance of round, oblong, and pear-shaped concentric bodies, little resembling the vessels from which they arose (Plate IV. Fig. 8).

8-JL. OF PATH. - VOL. III. 
No pathological changes could be found in any of the vessels of the pia mater of the cerebrum or cerebellum.

In connection with this case two other cases of "simple calcification" of the cerebral arteries were also studied.

The first (Mus. No. 2654) was from a man sixty-two years of age, who died from morbus Brightii complicated with ascites. There was found marked calcification of many of the arteries. The middle coat was most affected, but there were always numerous small round and irregular masses in the adventitia, and not unfrequently the lumen was occluded. In some of the capillaries were drops of colloid, of which the larger were calcified. After decalcification all the colloid substance stained deeply with hæmatoxylin.

In the second case (Mus. No. 2385), from a man fifty-six years of age, who died from emphysema complicated with ascites, the calcification of the arteries was also very marked, and microscopically the same appearances were found as in the case above. Many of the capillaries contained in their walls drops of colloid which were often calcified.

The study of these three cases shows that the colloid infiltration takes place in the arteries in the brain first, and most extensively in the middle coat, that it is found early in the adventitia but to a much less extent, and that, as a rule, the intima is last invaded as the vessel becomes occluded. It shows also that the deposit of lime salts takes place into the colloid material. The fine sandlike deposits were undoubtedly due to the calcified capillaries, and the stonelike concretions to the masses of capillaries bound together by calcified colloid material.

This manner of formation of concretions throws considerable light on a noted case reported by Bamberger and cited by Rokitansky ${ }^{1}$ in his "Pathological Anatomy."

In the brain of a woman thirty-four years old, for many years insane and subject to epileptic seizures especially at night, there was found besides calcification of the arteries, which "stuck up from the cut surface of the brain like the ends of so many wires," circumscribed areas in the corpora striata filled with yellow stonelike conglomerations.

Speaking of calcification in the brain in general, and of this case in particular, Rokitansky says: "There occur in the brain in the white substance, and also in various parts of the brain provided with grey matter, especially in the corpus striatum, for instance, areas in which the brain substance is replaced by a considerable conglomeration of simple and layered, smooth or nodular, yellowish, stony masses fragile as glass, which are identical in formation and substance with the sandlike deposits in the pineal gland. They are stuck together like glands of considerable size, and extending through the whole mass is a framework composed of vessels and of bundles of fibrous tissue. In these areas is to be seen a growth of connective tissue caused often, perhaps, by encephalitis, in which the fragments of the nerve tubes are ossified. A considerable

\footnotetext{
${ }^{1}$ Rokitansky, "Pathologische Anatomie," bd. ii. p. 472.
} 
number of the incrustations always adhere sheathlike to the vessels. In rare cases the blood vessels of the brain are surrounded by these masses in the shape of solid sheaths, also outside of the above mentioned areas."

I have quoted this description in full, on account of the accurate picture given of the appearances found in teased preparations. In all probability the areas of concretions described were calcified capillaries, such as were found in the first case detailed in this paper. Therefore, in the light of that case, I cannot agree with Rokitansky in regarding these concretions as the calcified remnants of nerve tubes.

Holschewnikoff ${ }^{1}$ reports an interesting case of a woman, 68 years old, in whom no brain symptoms were noted during life. Besides a "papilloma" beneath the cerebellum, the size of a small apple, and a similar tumour within the cerebellum, there were present in many parts of the cerebrum, but especially in the large ganglia, numerous areas of the size of pinheads and a little larger, which not infrequently contained friable, apparently calcareous, masses. Microscopically, after decalcification, sections through these areas showed, peripherally, colloid in beaded form, suggestive of capillary vessels; in the centre were masses and clumps of colloid which did not resemble capillaries, at whose expense they had been formed. In the tissue surrounding these areas was a network of capillaries with colloid masses, or drops in the walls. In the rest of the cerebrum he found veins with colloid in the adventitia, or in all three coats. The arteries were but little changed. This case can certainly be classed with the one that forms the basis of this work. But the process is much less extensive, and is confined to the cerebrum.

A third case worthy of notice is reported by Simon. ${ }^{2}$ In the cerebellum of an idiot, sixty-nine years old, there was found in the right hemisphere an irregularly round diseased area, somewhat over $2 \mathrm{~cm}$. in diameter, sharply limited by normal nervous substance. In the middle of the white matter of the left hemisphere was found a similar but smaller area hardly $\frac{3}{4} \mathrm{~cm}$. in diameter. Both areas were softer than the brain substance, but contained hard spots. In teased preparations were found "long, many-branched threads, undoubtedly calcified blood vessels," also round and long calcified bodies up to $3 \mathrm{~mm}$. in length. Nearly the whole capillary system, with the branches of the smaller arteries, was calcified, and appeared everywhere as composed of round calcified masses, which had become more or less melted together. The other form was like the grains of sand in psammomata. Simon concludes that the softening was secondary to the calcification of the vessels.

It is not at all improbable that it was especially the arteries and capillaries of the dentate nucleus that were involved in these diseased s. 552 .

1 Holschewnikoff, “Ueber Degeneration der Hirngefässe," Virchow's Archiv, bd. cxii.

${ }^{2}$ Simon, "Ausgedehnte Verkalkung der Hirngefässe bei einer Idiotin," Virchow's Archiv, bd. Iv. s. 534, 
areas, but without sections of the areas in situ no positive statement can be made.

There are other cases of concretions in the brain cited by Virchow, Lindsay, and others, which undoubtedly can justly be classed as owing their origin to the same degenerative processes in the blood vessels as are illustrated by the above mentioned cases; but these other cases are reported so briefly that it is impossible to determine their exact nature from the descriptions given.

For the term colloid which I have used in this paper, others would use the term hyaline, introduced into pathology by von Recklinghausen. If I still cling to the old name it has been done for the following reason. In the past there has been understood in pathology, under the term colloid, a degeneration of tissue elements into a substance which is homogeneous and not soluble in the fluids of the body. In the group of substances thus distinguished, mucin degeneration and amyloid formation have received separate names, because these forms of colloid, in the broad use of the term, are distinctly characterised by special chemical reactions, which render it possible to differentiate them from other forms of colloid. For these other forms it seems to me best to retain the term colloid, until each of these certainly different substances can be distinguished by some chemical reaction. I can find no reason for employing now a new name for this group, because the chemical reactions for the hyaline described by von Recklinghausen are not sufficiently characteristic. Moreover, it is to be noted that von Recklinghausen includes in his group of hyaline, formations which are certainly very different from the colloid substances, namely, the homogeneous masses in the diphtheritic membranes, and in blood coagulations.

The term colloid infiltration, instead of degeneration, of the blood vessels has been used, because the generally accepted view at present seems to be that the process is more an infiltration than a degenerative process.

Colloid infiltration of the blood vessels is not at all rare, especially in the brain, and it often occurs without calcification. The literature on this subject is abundant. In one case which came under my notice, where there was very extensive colloid infiltration of the blood vessels without any trace of calcification, and where death occurred in consequence of hæmorrhage into the basal ganglia, the colloid infiltration in the muscular coat could easily be studied in all its stages. It appeared as fine drops, which coalesced here and there in groups of muscle fibres, and apparently also between them. In the capillaries was abundant hyaline deposit.

A careful examination of the blood vessels in all parts of the body, in connection with the examination of the brain in such a case, might throw considerable light on the subject, and would prove an interesting field for further investigation.

For a study of the above described concretions in the brain it is. 

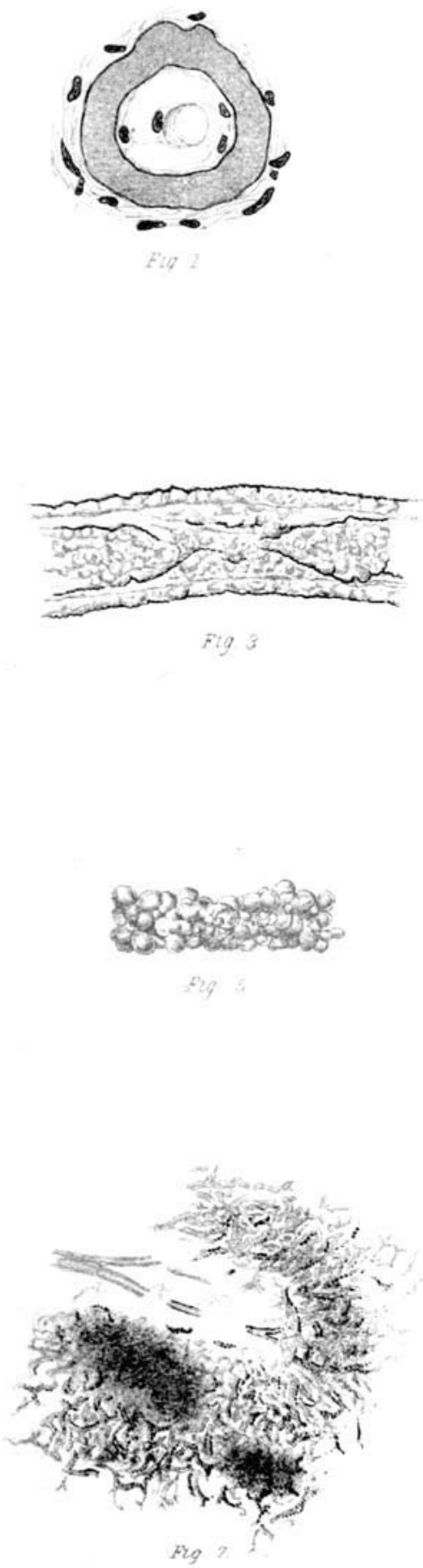
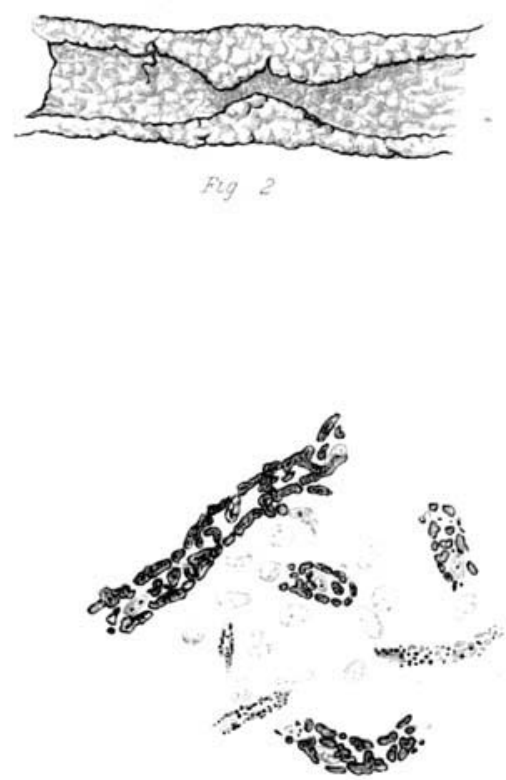

Fig 4
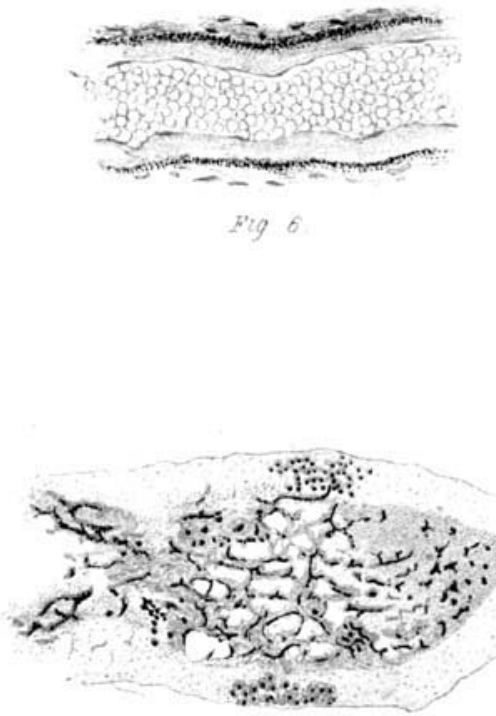

Fig \& 
indispensable, for a proper understanding of them, that they be examined in situ, by means of sections through them and the surrounding tissue, as well as in teased preparations.

The following conclusions may be drawn from the cases reported and cited :-

Colloid material in the brain is always deposited in the blood vessels. In the larger vessels the middle coat is earliest and most affected.

The colloid material has a tendency to undergo calcification.

The capillary network in certain parts of the brain, especially in the basal ganglia, in the grey matter of the cerebral cortex, in the dentate nucleus, and in the granular layer of the cerebellum, has a tendency, under certain conditions, to undergo colloid infiltration with calcification, leading to atrophy of the included nervous tissue, and to the formation of sandlike deposits, and of stonelike concretions.

I wish here to express my thanks to Prof. Chiari for the material placed at my disposal, and for his kindly oversight of my work.

\section{DESCRIPTION OF PLATE IV.}

FIG. 1.-Calcification of the tunica media in a small artery. (Decalcified). The intima is contracted away from the rigid media by the hardening in alcohol. Zeiss, Obj. E, Oc. 2. $(\times 390$.

FIG. 2.-Artery showing irregular calcified mass of colloid projecting into lumen. (Not decalcified.) Zeiss, Obj. AA, Oc. 4. (× 90.)

Fig. 3.-Artery showing complete occlusion of lumen. (Not decalcified.) Zeiss, Obj. AA, Oc. 4. $(\times 90$.

Fig. 4.-Precapillaries and capillaries showing small and large drops of colloid in the walls. (Decalcifier.) Zeiss, Obj. E, Oc. 4. $(\times 680$.

FIG. 5.-Precapillary showing nodular, colloid, and calcified, sheathlike wall. (Not decalcified.) Zeiss, Obj. E, Oc. 2. ( $\times$ 390.)

Fig. 6.--Vein showing colloid drops in the inner half of the adventitia. (Decalcified.) Zeiss, Obj. E, Oc. 2. ( $\times 390$.

FIG. 7.-Calcified network of the capillary system between the ganglion cells in the dentate nucleus. (Decalcified.) Zeiss, Obj. AA, Oc. 2. ( $\times$ 90.)

FIG. 8.-Section through a concretion in the cortex of the cerebellum. The holes are mainly due to portions of the colloid substance falling out of the section. (Decalcified.) Zeiss, Obj. AA, Oc. 2. ( × 90.) 